\title{
PENGARUH PEMBERIAN EDUKASI DENGAN METODE FOCUS GROUP DISCUSSION TERHADAP KEPATUHAN MINUM OBAT PENDERITA HIPERTENSI DI PUSKESMAS TAHUNA BARAT
}

\author{
Jesica F. Kansil \\ Mario E. Katuuk \\ Maria J. Regar \\ Program Studi Ilmu Keperawatan Fakultas Kedokteran \\ Universitas Sam Ratulangi \\ Email : jesica.fenessa@gmail.com
}

\begin{abstract}
Hypertension is one of the important factors as a trigger for Non Communicable Diseases such as Heart Disease, Stroke that were currently the number one cause of death in the world. Adherence in managing hypertension was very important because it can be affect the patient's life in managing the disease. The effort that can be given to improve adherence was provided education. The Purpose: to know the effect of providing education with FGD Method towards medication adherence of hypertensive patients. This research method: is quasi experiment, with pretest-posttest with control group design. Samples: Sampling techniques in this research is purposive sampling of 34 respondents who have a criteria inclusion that consist of 17 respondents of intervention group and 17 respondents of control group. Data accumulation is using the questionnaire with 10 questions. The Results: by using Chi Square test at a significance level of $95 \%$, obtained a significant value $p=0.028$ or smaller than 0.05 (0.028< 0.05). Conclusions: that educational of FGD method is very effectively to improve medication adherence of hypertensive patients at Public Health Center of West Tahuna.
\end{abstract}

Keywords : Education, FGD Method, Medication Adherence

\begin{abstract}
Abstrak : Hipertensi merupakan salah satu faktor penting sebagai pemicu Penyakit Tidak Menular seperti Penyakit Jantung, Stroke dan lain-lain yang saat ini menjadi penyebab kematian nomor satu di dunia. Kepatuhan dalam memanajemen hipertensi sangat penting karena dapat mempengaruhi cara hidup pasien dalam mengelolah penyakitnya. Upaya yang bisa diberikan untuk meningkatkan kepatuhan yaitu dengan pemberian edukasi. Tujuan untuk mengetahui pengaruh pemberian edukasi dengan metode FGD terhadap kepatuhan minum obat penderita hipertensi. Metode penelitian ini adalah quasi eksperimen, dengan desain penelitian pretest-posttest with control group. Teknik sampling dalam penelitian ini adalah purposive sampling berjumlah 34 responden yang telah memenuhi kriteria inklusi yang terdiri dari kelompok intervensi 17 responden dan kelompok kontrol 17 responden. Pengumpulan data menggunakan kuesioner sebanyak 10 pertanyaan. Hasil penelitian dengan menggunakan uji Chi Square pada tingkat kemaknaan $95 \%$ diperoleh nilai signifikan $\mathrm{p}=$ 0.028 atau lebih kecil dari $0.05(0.028<0.05)$. Kesimpulan, hasil penelitian ini menunjukkan bahwa metode edukasi dengan FGD sangat efektif digunakan untuk meningkatkan kepatuhan minum obat penderita hipertensi di Puskesmas Tahuna Barat.
\end{abstract}

Kata Kunci : Edukasi, Metode FGD, Kepatuhan Minum Obat 


\section{PENDAHULUAN}

Hipertensi merupakan salah satu faktor penting sebagai pemicu Penyakit Tidak Menular (Non Communicable Disease) seperti Penyakit Jantung, Stroke dan lain-lain yang saat ini menjadi penyebab kematian nomor satu di dunia (Kementrian Kesehatan, 2015). Hipertensi berkaitan dengan peningkatan tekanan darah sistolik sedikitnya $140 \mathrm{mmHg}$ atau tekanan diastolic sedikitnya $90 \mathrm{mmHg}$ maupun tekanan keduanya. Semakin tinggi tekanan darah, maka semakin besar resiko terjadi komplikasi (Nurarif \& Kusuma, 2015). World Health Organization (WHO) tahun 2012, menyebutkan di seluruh dunia sekitar 972 juta orang menderita hipertensi. Dari 972 juta penderita hipertensi, 333 juta berada di Negara maju dan 639 juta sisanya di Negara berkembang. Kementrian Kesehatan (2018), memperkirakan pada tahun 2025 mendatang, sekitar 1,6 miliar orang dewasa di seluruh dunia menderita hipertensi.

Prevalensi hipertensi di Indonesia berdasarkan data Riset Kesehatan Dasar 2018 mengalami kenaikan dari 25,8\% (68,9 juta orang) menjadi $34,1 \%(90,1$ juta orang). Prevalensi tertinggi terjadi di Kalimantan Selatan dan yang terendah di Papua. Sementara itu, di Sulawesi Utara penderita hipertensi sekitar 13,2 \%. Hipertensi ini dikenal sebagai silent killer karena gejalanya tanpa keluhan dan nanti diketahui saat sudah terjadi komplikasi (KemenKes, 2018). Tidak terkontrolnya hipertensi dapat menyebabkan terjadinya komplikasi kardiovaskular. Komplikasi dari Hipertensi terbanyak adalah Stroke, Penyakit Jantung Koroner, Kebutaan (KemenKes, 2018). Penelitian yang dilakukan oleh Yufli, dkk (2014) tentang prevalence of hypertension and its complication in Jatinangor 2014, menunjukkan bahwa komplikasi akibat hipertensi di Jatinangor sebanyak 33,9\% dan yang paling umum terjadi yaitu serangan jantung dan stroke. Untuk menghindari komplikasi dari hipertensi diperlukan keteraturan dalam meminum obat.

Obat-obat antihipertensi yang ada saat ini sudah terbukti bisa mengontrol tekanan darah pada penderita hipertensi, dan mempunyai peran penting dalam menurunkan resiko berkembangnya komplikasi kardiovaskular (Chobanian, 2004). Namun, penggunaan obat antihipertensi saja tidak cukup untuk menghasilkan efek pengendalian tekanan darah jangka panjang jika tidak didukung dengan kepatuhan dalam mengkonsumsi obat antihipertensi tersebut (Schroeder, et al 2004). Penelitian yang dilakukan oleh Pratama dan Ni (2014) pada lansia binaan Puskesmas Klungkung 1 menunjukkan rendahnya kepatuhan pengobatan hipertensi, dari 97 responden, sebanyak 62 responden $(63 \%)$ memiliki kepatuhan yang rendah dan yang memiliki tingkat kepatuhan tinggi hanya 35 responden $(36.1 \%)$. Penelitian yang dilakukan oleh Sinuraya, dkk (2018) mengenai tingkat kepatuhan pengobatan pasien hipertensi di fasilitas kesehatan tingkat pertama di Kota Bandung, juga menunjukkan masih rendahnya kepatuhan pengobatan hipertensi. Dari 226 responden, sebanyak 121 responden $(53,5 \%)$ memiliki kepatuhan yang rendah, 73 responden $(32,3 \%)$ memiliki kepatuhan sedang dan 32 responden $(14,2 \%)$ memiliki tingkat kepatuhan tinggi. Kepatuhan dalam memanajemen hipertensi sangat penting karena dapat mempengaruhi cara hidup pasien dalam mengelolah penyakitnya.

\begin{tabular}{llll}
\multicolumn{2}{c}{ Masalah ketidakpatuhan } & pada \\
umumnya sering dijumpai & pada \\
pengobatan & penyakit kronis & yang
\end{tabular}
memerlukan pengobatan jangka panjang (Osterberg \& Terrence, 2005). Oleh karena itu, berbagai upaya harus dilakukan untuk meningkatkan kepatuhan penggunaan obat pada pasien hipertensi. Guirado, et al (2011) menjelaskan bahwa pemberian intervensi merupakan faktor penting dalam perubahan sikap kepatuhan pengobatan hipertensi seperti kepatuhan diet, kepatuhan minum obat, dan kepatuhan 
aktivitas sehari-hari. Upaya yang bisa diberikan agar kepatuhan meningkat yaitu dengan pemberian edukasi. Penelitian yang dilakukan oleh Hadi (2015) menunjukkan bahwa pendidikan kesehatan mempunyai pengaruh terhadap peningkatan pengetahuan tentang hipertensi. Penelitian yang dilakukan oleh Harwandy dan Nurul (2017) di Puskesmas Kasihan 1 Bantul, juga menunjukkan bahwa edukasi mempunyai pengaruh terhadap peningkatan kepatuhan minum obat dan kontrol tekanan darah pada pasien hipertensi. Metode edukasi yang efektif untuk digunakan secara garis besar yaitu metode Didaktif dan Sokratik (Maulana, 2009). Salah satu metode yang efektif digunakan yaitu dengan FGD. FGD adalah suatu metode pengumpulan data/informasi individu dalam suatu kelompok diskusi, tujuannya untuk mendorong peserta berkomunikasi satu dengan yang lain, bertukar ide-ide dan berbagi pengalaman dan mengungkapkan pemahaman serta pendapatnya secara bebas untuk memecahkan suatu masalah (Wong, 2008). Keuntungan penggunaan FGD ini yaitu mampu menggali informasi yang mendalam mengenai pengetahuan, sikap dan persepsi individu dalam suatu kelompok tentang suatu masalah (Afiyati, 2008). Penelitian mengenai pengaruh FGD terhadap penyakit TB Paru yang pernah dilakukan oleh Octavia (2015), menunjukkan bahwa penelitian dengan FGD ini efektif, karena terjadi peningkatan pengetahuan setelah diberikan edukasi pada pasien dengan TB Paru. Penelitian yang dilakukan oleh Kusdiahsari (2015) juga menunjukkan bahwa ada pengaruh pemberian pendidikan kesehatan dengan FGD terhadap minat remaja mengkonsumsi makanan tinggi serat.

Data awal yang didapatkan dari Puskesmas Tahuna Barat, terdapat 112 kasus hipertensi pada bulan Agustus Oktober di tahun 2018, dan berdasarkan wawancara dengan petugas kesehatan, para pasien hipertensi ini telah mendapatkan edukasi mengenai hipertensi, tetapi dikatakan bahwa kasus hipertensi terus meningkat dari tahun sebelumnya. Wawancara yang dilakukan kepada 10 pasien di Puskesmas Tahuna Barat, 7 pasien mengatakan bahwa pasien malas atau tidak meminum obat yang diberikan dan nanti meminum obat saat sudah mulai merasa sakit. 3 pasien lainnya mengatakan meminum obat yang diberikan, tetapi terkadang lupa meminum obat jika sudah sibuk dengan pekerjaan. Berdasarkan uraian diatas, maka peneliti tertarik untuk mengetahui pengaruh pemberian edukasi dengan metode FGD terhadap kepatuhan minum obat penderita hipertensi di Puskesmas Tahuna Barat.

\section{METODE PENELITIAN}

Desain penelitian ini merupakan penelitian kuantitatif, dengan menggunakan metode quasi experiment design dengan rancangan pre and post test with control group (Setiadi, 2013). Penelitian ini dilaksanakan di Puskesmas Tahuna Barat pada bulan Januari-Maret 2019. Populasi dalam penelitian ini adalah penderita hipertensi yang ada di Puskesmas Tahuna Barat yang berjumlah 112 orang. Teknik pengambilan sampel dilakukan secara non probability sampling yaitu purposive sampling. Ukuran sampel dalam penelitian ini menggunakan penarikan sampel eksperimental design, dengan penentuan 15 sampel per kelompok (Yunita, 2016). Dengan menggunakan rumus resiko drop out di dapatkan sampel 17 responden. Sehingga jumlah sampel dalam penelitian ini sebanyak 34 responden. Instrumen penelitian yang digunakan untuk mengukur kepatuhan minum obat menggunakan kuesioner yang sudah digunakan sebelumnya oleh Sumantara (2017) yang terdiri dari 10 pertanyaan, dengan pilihan jawaban ya dan tidak dengan kriteria skor 2= ya, 1= tidak.

Pengolahan data yang diperoleh dari hasil penelitian ini diolah secara manual dengan mengelompokkan hasil wawancara dan observasi kemudian dilakukan penghitungan skor dan dianalisis 
menggunakan uji statistik melalui sistem komuterisasi dengan beberapa tahap yaitu editing, coding, entering, cleaning (Notoatmodjo, 2012). Analisa bivariat menggunakan uji Mc Nemar untuk menguji perbedaan kepatuhan minum obat pada kelompok intervensi dan kelompok kontrol sebelum dan setelah diberikan edukasi. Dan uji Chi-Square untuk menguji perbedaan kepatuhan minum obat setelah diberikan edukasi pada kelompok intervensi dan kelompok kontrol, dengan tingkat kemaknaan $95 \%(a=0,05)$.

\section{HASIL dan PEMBAHASAN}

\section{Analisa Univariat}

Tabel 1. Analisis Kepatuhan Minum Obat pre-test dan post-test Kelompok Kontrol

\begin{tabular}{ccccc}
\hline Kategori & \multicolumn{2}{c}{ Pre-Test } & \multicolumn{2}{c}{ Post-Test } \\
\cline { 2 - 5 } & $\mathbf{n}$ & $\boldsymbol{\%}$ & $\mathbf{n}$ & $\mathbf{\%}$ \\
\hline Patuh & 5 & 29.4 & 8 & 47.1 \\
\hline Tidak Patuh & 12 & 70.6 & 9 & 52.9 \\
\hline Total & $\mathbf{1 7}$ & $\mathbf{1 0 0 . 0}$ & $\mathbf{1 7}$ & $\mathbf{1 0 0 . 0}$ \\
\hline Sumber : Data Primer 2019 & &
\end{tabular}

Hasil penelitian menunjukkan bahwa kepatuhan minum obat pre-test pada kelompok kontrol dari 17 responden, 5 responden $(29.4 \%)$ patuh dan kepatuhan minum obat post-test pada kelompok kontrol meningkat menjadi 8 responden $(47.1 \%)$ yang patuh. Hasil penelitian ini menunjukkan bahwa pemberian edukasi dengan ceramah mempunyai pengaruh terhadap tingkat kepatuhan pasien hipertensi walaupun tidak signifikan. Hal ini disebabkan karena kebanyakan responden sudah jenuh mengikuti penyuluhan dengan metode yang sudah biasa sehingga menyebabkan kurangnya intensitas perhatian responden pada apa yang disampaikan oleh peneliti. Perubahan sikap pada dasarnya dipengaruhi oleh faktor pengetahuan dan kepercayaan/keyakinan yang didapatkan dari hasil pengindraan, yang salah satunya didapatkan melalui pemberian pendidikan kesehatan.
Tabel 2. Analisis Kepatuhan Minum obat pre-test dan post-test Kelompok Intervensi

Kategori Pre-Test Post-Test

\begin{tabular}{ccccc}
\hline Patuh & 7 & 41.2 & 15 & 88.2 \\
\hline Tidak Patuh & 10 & 58.8 & 2 & 11.8 \\
\hline Total & $\mathbf{1 7}$ & $\mathbf{1 0 0 . 0}$ & $\mathbf{1 7}$ & $\mathbf{1 0 0 . 0}$ \\
\hline Sumber : Data & Primer 2019 & &
\end{tabular}

Berdasarkan hasil menunjukkan bahwa kepatuhan minum obat pre-test pada kelompok intervensi dari 17 responden, 7 responden $(41.2 \%)$ patuh, dan kepatuhan minum obat post-test pada kelompok intervensi meningkat menjadi 15 responden $(88.2 \%)$ patuh. Dari hasil penelitian dapat disimpulkan bahwa kepatuhan minum obat kelompok intervensi sebelum dan setelah diberikan edukasi dengan metode FGD mengalami peningkatan yang signifikan. Hal ini disebabkan karena metode edukasi dengan FGD menarik perhatian responden untuk memperhatikan dan fokus pada apa yang disampaikan peneliti sehingga informasi yang diberikan peneliti diterima dengan baik oleh responden, juga diikuti dengan diskusi kelompok yang mendorong keaktifan peserta dalam proses diskusi, sehingga materi yang belum dapat didiskusikan.

\section{Analisa Bivariat}

Tabel 3. Analisis Perbedaan Kepatuhan Minum Obat Pre-Test dan Post-test Responden Kelompok Intervensi

\begin{tabular}{|c|c|c|c|c|c|}
\hline \multirow[t]{2}{*}{ Kategori } & \multicolumn{2}{|c|}{ Pre-Test } & \multicolumn{2}{|c|}{ Post-Test } & \multirow{2}{*}{$\begin{array}{c}\text { p- } \\
\text { Value }\end{array}$} \\
\hline & $\mathbf{n}$ & $\%$ & $\mathbf{n}$ & $\%$ & \\
\hline Patuh & 7 & 41.2 & 15 & 88.2 & 0.008 \\
\hline $\begin{array}{l}\text { Tidak } \\
\text { Patuh }\end{array}$ & 10 & 58.8 & 2 & 11.8 & \\
\hline Total & 17 & 100.0 & 17 & $\begin{array}{c}100 . \\
0\end{array}$ & \\
\hline
\end{tabular}

Sumber : Data Primer 2019

Analisis perbedaan kepatuhan minum obat pre-test dan post-test kelompok intervensi dengan hasil uji $M C$ 
Nemar diperoleh nilai p-value 0.008 . Dimana nilai $\mathrm{p}$-value $\leq 0,05$, yang berarti terdapat perbedaan kepatuhan minum obat pre-test dan post-test pada kelompok intervensi yang diberikan edukasi dengan metode FGD. Hasil penelitian ini menunjukkan bahwa pemberian edukasi dengan menggunakan Metode FGD mempunyai pengaruh terhadap tingkat kepatuhan pasien hipertensi. Pada penelitian ini terdapat perbedaan kepatuhan minum obat kelompok intervensi sebelum dan setelah diberikan edukasi dengan metode FGD. Pemberian edukasi dengan metode yang baik dan tepat dapat membantu meningkatkan kepatuhan pasien hipertensi sehingga tekanan darah berada pada rentang yang normal dan komplikasi akibat hipertensi dapat dicegah dan dikontrol. Kepatuhan dalam pengobatan dapat diartikan sebagai perilaku pasien yang mentaati semua nasehat dan petunjuk yang dianjurkan oleh tenaga kesehatan (Fauzi \& Khairu, 2018).

Tabel 4. Analisis Perbedaan Kepatuhan Minum Obat Pre-Test dan Post-test Responden Kelompok Kontrol

\begin{tabular}{|c|c|c|c|c|c|}
\hline \multirow[t]{2}{*}{ Kategori } & \multicolumn{2}{|c|}{ Pre-Test } & \multicolumn{2}{|c|}{ Post-Test } & \multirow{2}{*}{$\begin{array}{c}\text { p- } \\
\text { Value }\end{array}$} \\
\hline & $\mathbf{n}$ & $\%$ & $\mathbf{n}$ & $\%$ & \\
\hline Patuh & 5 & 29.4 & 8 & 47.1 & 0.250 \\
\hline $\begin{array}{l}\text { Tidak } \\
\text { Patuh }\end{array}$ & 12 & 70.6 & 9 & 52.9 & \\
\hline Total & 17 & 100.0 & 17 & $\begin{array}{c}100 . \\
0\end{array}$ & \\
\hline
\end{tabular}

Sumber : Data Primer 2019

Hasil uji menggunakan MC Nemar diperoleh $\rho$ value $=0,250>0,05$. Hasil penelitian ini menunjukkan bahwa pemberian edukasi dengan menggunakan metode Ceramah tidak memberikan pengaruh yang signifikan terhadap kepatuhan minum obat responden. Hal ini disebabkan karena kebanyakan responden sudah bosan mengikuti penyuluhan dengan metode yang sudah biasa sehingga menyebabkan kurangnya perhatian responden pada apa yang disampaikan oleh peneliti sehingga informasi yang diberikan oleh peneliti tidak dapat ditangkap dan diterima dengan baik oleh responden. Pemberian edukasi dengan metode ceramah akan berhasil apabila mendapatkan perhatian yang sungguhsungguh dari peserta. Pemberian edukasi kesehatan pada pasien hipertensi merupakan usaha yang dilakukan dalam rangka memberikan informasi terhadap masalah-masalah kesehatan yang dialami oleh pasien. Tujuannya untuk membuat pasien mengerti dan memahami masalah kesehatan yang dialaminya, dan meningkatkan pengetahuan serta kepatuhan pasien dalam pengobatannya untuk mencapai kesehatan secara optimal (Nursalam, 2008).

Tabel 5. Analisis Perbedaan Kepatuhan Minum Obat Post-test Responden Kelompok Intervensi dan Kelompok Kontrol

\begin{tabular}{|c|c|c|c|c|c|}
\hline \multirow[t]{2}{*}{ Kategori } & \multicolumn{2}{|c|}{$\begin{array}{l}\text { Kelompok } \\
\text { Intervensi }\end{array}$} & \multicolumn{2}{|c|}{$\begin{array}{c}\text { Kelompok } \\
\text { Kontrol }\end{array}$} & \multirow{2}{*}{$\begin{array}{c}\text { p- } \\
\text { Val } \\
\text { ue }\end{array}$} \\
\hline & $\mathbf{n}$ & $\%$ & $\mathbf{N}$ & $\%$ & \\
\hline Patuh & 15 & 88.2 & 8 & 47.1 & 0.02 \\
\hline $\begin{array}{l}\text { Tidak } \\
\text { Patuh }\end{array}$ & 2 & 11.8 & 9 & 52.9 & 8 \\
\hline Total & 17 & 100.0 & 17 & 100.0 & \\
\hline
\end{tabular}

Sumber : Data Primer 2019

Hasil analisa diatas menunjukkan kepatuhan minum obat post-test kelompok intervensi dan kelompok kontrol dimana pada kelompok intervensi sebanyak 15 responden $(88.2 \%)$ patuh dan tidak patuh 2 responden $(11.8 \%)$. Sedangkan pada kelompok kontrol sebanyak 8 responden $(47.1 \%)$ patuh dan yang tidak patuh 9 responden (52.9 \%). Hasil uji statistik menggunakan uji chi square mendapatkan nilai $p$-value 0.028 . Nilai $p$-value $\leq 0,05$, yang berarti terdapat perbedaan kepatuhan minum obat post-test pada kelompok intervensi dan kelompok kontrol. Dengan demikian sesuai dengan dugaan awal peneliti bahwa terdapat pengaruh pemberian edukasi dengan metode FGD terhadap kepatuhan minum obat penderita 
hipertensi. Hasil penelitian ini sejalan dengan penelitian Ginting (2014) tentang efektifitas FGD terhadap peningkatan smoking self efficacy pada kelompok pria dewasa awal kategori sedang. Dalam penelitiaannya didapatkan hasil bahwa FGD efektif meningkatkan perilaku pada seluruh perokok untuk mengontrol keinginan merokok.

Metode Ceramah adalah metode memberikan informasi, motivasi, dan pengaruh terhadap cara berpikir sasaran mengenai satu topik (Nursalam, 2008). Dalam metode ceramah, peserta bersifat pasif dan tidak diberi kesempatan untuk berdiskusi dan mengemukakan pendapatnya. FGD merupakan suatu proses pengumpulan data dan informasi yang sistematis mengenai suatu permasalahan tertentu yang sangat spesifik melalui diskusi kelompok (Irwanto, 2006). Dalam metode FGD, peserta bersifat aktif dan diberi kesempatan untuk berdiskusi menyampaikan pendapatnya tentang suatu masalah dan berbagi pengalaman dengan peserta lainnya. Adifta dan Bayu (2016) dalam penelitiannya tentang perbedaan efektivitas penyuluhan kesehatan reproduksi antara metode ceramah dan FGD menyebutkan bahwa metode FGD lebih efektif digunakan dalam meningkatkan pengetahuan dan sikap terkait kesehatan reproduksi dibandingkan dengan metode ceramah. Metode edukasi dengan FGD lebih berpengaruh dibandingkan dengan metode ceramah. Hal ini dapat dilihat dari jawaban pada kuesioner responden kelompok intervensi yang diberikan edukasi dengan metode FGD, dimana sebagian besar responden mengalami peningkatan kepatuhan setelah diberikan edukasi. Dan dilihat dari keaktifan pada proses penelitian, kelompok intervensi yang diberikan edukasi dengan metode FGD lebih aktif dan sangat antusias mengikuti penelitian. Ketika peneliti memberikan pertanyaan, mereka menjawab semua pertanyaan yang diberikan oleh peneliti dan saling terbuka menyampaikan pendapat dan menceritakan tentang pengalaman mereka. Dan pada saat peneliti memberikan materi, responden kelompok intervensi sangat memperhatikan dan focus pada apa yang disampaikan peneliti. Ketika diberi kesempatan untuk bertanya mereka sangat antusias dan memberikan pertanyaan mengenai hal yang mereka rasa belum jelas. Berbeda dengan kelompok kontrol yang diberikan edukasi dengan metode ceramah. Mereka lebih pasif dan pada saat peneliti memberikan materi, hanya sebagian yang mendengarkan apa yang disampaikan peneliti sedangkan responden yang lainnya sibuk dengan urusan masingmasing. Bahkan, ada responden yang tertidur pada saat peneliti memberikan materi.

Edukasi kesehatan dengan metode FGD efektif dalam peningkatan kepatuhan pada pasien hipertensi. Metode yang lebih menarik membantu pasien dalam penyerapan informasi-informasi yang diberikan. Metode FGD membantu para responden untuk menerima penyakitnya karena dihadapkan dengan para responden yang juga menderita penyakit yang sama, sehingga bisa berbagi pengalaman dan juga bertukar pendapat melalui diskusi kelompok tersebut. Efendy dan Makhfudli (2009), mengatakan bahwa promosi kesehatan adalah upaya memberdayakan perorangan, kelompok dan masyarakat agar memelihara, meningkatkan, dan melindungi kesehatannya melalui peningkatan pengetahuan, kemauan, dan kemampuan untuk berperilaku hidup bersih dan sehat. Dengan pemberian edukasi menggunakan metode yang tepat, maka responden akan terdorong untuk patuh pada pengobatan yang mereka jalani.

\section{SIMPULAN}

Kepatuhan minum obat responden sebelum diberikan edukasi dengan metode focus group discussion yaitu tidak patuh dan meningkat secara signifikan setelah diberikan edukasi. Dengan demikian terdapat pengaruh pemberian edukasi dengan metode focus group discussion 
terhadap kepatuhan minum obat penderita hipertensi di Puskesmas Tahuna Barat.

\section{DAFTAR PUSTAKA}

Adifta \& Bayu (2016). Perbedaan Efektivitas Penyuluhan Kesehatan Reproduksi Antara Metode Ceramah Dan Focus Group Discussion.

Afiyati, Y. (2008). Focus Group Discussion (Diskusi Kelompok Terfokus) sebagai Metode Pengumpulan Data Penelitian Kualitatif. Jurnal Keperawatan Indonesia, Vol. 12 No.1. Hal 58-62.

Chobanian, A.V. (2003). Seventh Report of the Joint National Committee on Prevention, Detection, Evaluation, and Treatment of High Blood Pressure. Hypertension., 42 (6) : 1206-1252.

Effendi, F., \& Makhfudli. (2009). Keperawatan Kesehatan Komunitas. Jakarta: Salemba Medika.

Fauzi, R., \& Khairu, N. (2018). Apoteker Hebat, Terapi Taat, Pasien Sehat. Yogyakarta: Stiletto Indie Book.

Ginting, M.D.F. (2014). Efektivitas Focus Group Discussion Terhadap Peningkatan Smoking Self Efficacy Pada Kelompok Pria Dewasa Awal Kategori Perokok Sedang. Program Pendidikan Magister Psikologi Profesi Fakultas Psikologi Universitas Sumatera Utara.

Guirado, E.A., Enriqueta, P.R., Valeria, P.H., \& Josep, M.B. (2011). Knowledge And Adherence To Antihypertensive Therapy In Primary Care: Results Of A Randomized Trial. Gac Sanit., 25 (1) : 62-67.

Hadi, C. (2015). Efektivitas Pendidikan Kesehatan terhadap Peningkatan Pengetahuan Keluarga tentang
Hipertensi. Mutiara Medika, Vol. 15. No.1. Hal. 67-74.

Harwandy \& Nurul, M. (2017). Pengaruh Edukasi Terhadap Tingkat Kepatuhan Pada Pasien Hipertensi di Puskesmas Kasihan 1 Bantul.

Irwanto. (2006). Pengantar Praktis. Focused Group Discussion (FGD). Jakarta : Pustaka Obor Indonesia.

Kementrian Kesehatan Republik Indonesia. (2015). Hipertensi , The Silent Killer. https://www.pusdatin.kemkes.go.id.

$\begin{array}{ccr}\text { Kementrian } & \text { Kesehatan } & \text { Republik } \\ \text { Indonesia. } & (2018) . & \text { Hipertensi } \\ \text { Membunuh } & \text { Diam-Diam, } & \text { Ketahui } \\ \text { Tekanan } & \text { Darah } & \text { Anda. } \\ \text { https://www.depkes.go.id. } & \end{array}$

Kusdiahsari, K. (2015). Pengaruh Pemberian Pendidikan Kesehatan Metode Focus Group Discussion (FGD) terhadap Minat Remaja Mengkonsumsi Makanan Tinggi Serat. (Skripsi Ilmiah). PSIK Fakultas Ilmu Kesehatan. Universitas Muhammadyah Malang.

Maulana, H. (2009). Promosi Kesehatan. Jakarta : EGC.

Nursalam. (2008). Pendidikan Dalam Keperawatan. Jakarta: Salemba Medika.

Notoatmodjo. (2012). Metodologi Penelitian Kesehatan. Jakarta : PT Rineka Cipta.

Nurarif A., \& Kusuma, A. (2015). Aplikasi Asuhan Keperawatan Berdasarkan Diagnosa Medis Dan Nanda NicNoc Edisi Revisi Jilid 2. Yogyakarta : Mediaction Publishing.

Octavia, E. (2015). Pengaruh Pemberian Edukasi dengan Metode FGD 
e-journal Keperawatan(e-Kp) Volume 7 Nomor 1, Mei 2019

terhadap Penderita TB Paru di PKM Sampang Madura. Jurnal Keperawatan.

Osterberg, L., \& Terrence, B. (2005). Adherence of Medication. The New England Journal Of Medicine, 353 (5), 487-497.

Pratama, G.W., \& Ni, L.P.A. (2014). Faktor-Faktor Yang Mempengaruhi Kepatuhan Pengobatan Hipertensi Pada Lansia Binaan Puskesmas Klungkung 1. Jurnal Ilmu Kedokteran Komunitas.

Riset Kesehatan Dasar. (2018). Hasil Utama Riskesdas 2018. https://www.depkes.go.id.

Schroeder, K., Tom, F., \& Shah, E. (2004). How Can We Improve Adherence to Blood Pressure-Lowering Medication in Ambulatory Care ?. Arch Intern Med.,164, 722-732.

Setiadi. (2013). Konsep dan Praktis Penulisan Riset Keperawatan. Ed 2. Yogyakarta : Graha Ilmu.

Sinuraya, R. K., Dika, P.D., Irma, M.P., \& Ajeng, D. (2018). Tingkat Kepatuhan Pengobatan Pasien Hipertensi Di Fasilitas Kesehatan Tingkat Pertama Di Kota Bandung. Jurnal Farmasi Klinik Indonesia.Vol. 7, No. 2, Hal. 124-133. ISSN : 2252-6218. Doi : 10.15416/ijcp.2018.7.2.124.

Sumantara, I.G. (2017). Hubungan Dukungan Informatif dan Emosional Keluarga dengan Kepatuhan Minum Obat Pada Lansia Hipertensi di Puskesmas Ranomuut Kota Manado. E-Jurnal Keperawatan (e-Kep), Vol.5, No.1.

World Health Organization. (2012). Health Topics. Medical Education. https://www.who.int.
Wong, L.P. (2008). Focus Group Discussion : A Tool For Health and Medical Research. Singapore Medical Journal, 49 (3), 256-261.

Yufli F.F., Sofiatin, Paulus A., Hadyana \& Rully M.A. (2014). Prevalence Of Hypertension And Its Complication In Jatinangor 2014. Journal Of Hypertension.

Doi 10.1097/01.hjh.0000469851.39188.3 6.

Yunita, L. (2016). Efektifitas Pendidikan Kesehatan Dengan Metode Ceramah Terhadap Tingkat Pengetahuan Ibu Dalam Penanganan Diare Balita Di Sekitar UPT TPA Cipayung Depok Tahun 2016. [Skripsi Ilmiah]. Jakarta : PSIK Fakultas Kedokteran dan Ilmu Kesehatan Universitas Islam Negeri Syarif Hidayatullah.in : Gay \& Diehl (1992). Sampel Penelitian Eksperimen 